\title{
THE BARTLETT-EDWARDS INCENTIVE SPIROMETER: A PRELIMINARY ASSESSMENT OF ITS USE IN THE PREVENTION OF ATELECTASIS AFTER CARDIO-PULMONARY BYPASS
}

\author{
G.D. GALE ${ }^{*}$ aND D.E. SANDERS ${ }^{\dagger}$
}

Patients undergoing cardiac operations have a high incidence of hypoxia due to pulmonary atelectasis (Table I) despite careful management of fluids in an attempt to prevent pulmonary oedema from fluid overload. The management of these patients has included vigorous physiotherapy and intermittent positive pressure breathing treatments (IPPB). Many authors have endorsed this form of treatment with enthusiasm, although there is no evidence in the literature that IPPB is effective in these situations.

For several years there have been reports of the use of the incentive spirometer as an alternative to IPPB. The technique relies on the active participation of the patient to produce large tidal volumes through voluntary maximal inspirations or yawning. ${ }^{5}$ This has been shown to be effective in reducing the incidence of pulmonary atelectasis in patients after adrenalectomy ${ }^{6}$ and elective laparotomy. ${ }^{7}$

This study was carried out to assess the effects of the incentive spirometer in patients who had undergone open-heart operations and also to determine the incidence of atelectasis in this group of patients.

In this study atelectasis was classified on radiological evidence as plate, subsegmental, segmental or lobar in type. Plate atelectasis (synonymous with disk atelectasis) is described by Fraser and Paré ${ }^{8}$ and was originally described by Fleischner. ${ }^{9}$ It consists of linear densities almost always in the lung bases, roughly horizontal or slightly oblique, varying in thickness from one to three millimeters and commonly several centimeters in length. Lines due to plate atelectasis invariably extend to the pleural surface.

\section{METHOD}

\section{The Incentive Spirometer}

The Bartlett-Edwards Incentive Spirometer (Edwards Laboratories, Figure 1) consists of a cylinder and piston with an adjustable volume of 200 to $2,500 \mathrm{ml}$. On top of the cylinder there is a volume indicator, a battery-operated light bulb and an incidence counter. An airway hose leads from the top of the cylinder to a mouthpiece. The patient inhales through the mouthpiece and draws air from the cylinder causing the piston to rise. When the predetermined volume is reached the incidence counter is tripped and a switch is closed turning on the light. There is a small constant leak in the spirometer so that the patient must continue to inhale to keep the light on. When inspiratory flow ceases the piston falls and the

Departments of Anaesthesia ${ }^{\circ}$ and Radiology, $\uparrow$ University of Toronto, and Toronto General Hospital, Toronto, Ontario, Canada. 
TABLE I

The Reported Incidence of Pulmonary Complications after Cardiopulmonary Bypass. The Author, the Year and the Percentage Reported are Shown

\begin{tabular}{lcc}
\hline \hline & Year & $\begin{array}{c}\text { Per cent incidence of } \\
\text { pulmonary complications }\end{array}$ \\
\hline Provan, et al. ${ }^{1}$ & 1966 & 61.5 \\
Gaulert, et al. ${ }^{2}$ & 1971 & 70 \\
Templeton, et al. ${ }^{3}$ & 1966 & 74 \\
Turnbull, et al. & 1974 & 84.3 \\
\hline
\end{tabular}

light goes out. The sitting position is recommended for the patient who is asked to breath out into the room and then take a big breath from the mouthpiece so that the light goes on. He then keeps the light on as long as possible by breathing in and then he exhales slowly. The light provides the patient with a visual reward for reaching the pre-set inspiratory volume. Enough time should be allowed between breaths to prevent patient fatigue. In this study treatments lasted about 20 minutes and were repeated four times a day. We have added a one-ivay valve to the mouthpiece so that when the patient exhales he does so to atmosphere without contaminating the spirometer.

The method chosen was to measure the changes in vital capacity and in arterial oxygen tension $\left(\mathrm{Pa}_{\mathrm{O}_{2}}\right)$ as reflections of the patient's ability to take a deep breath and the degree of shunting occurring within the lung.

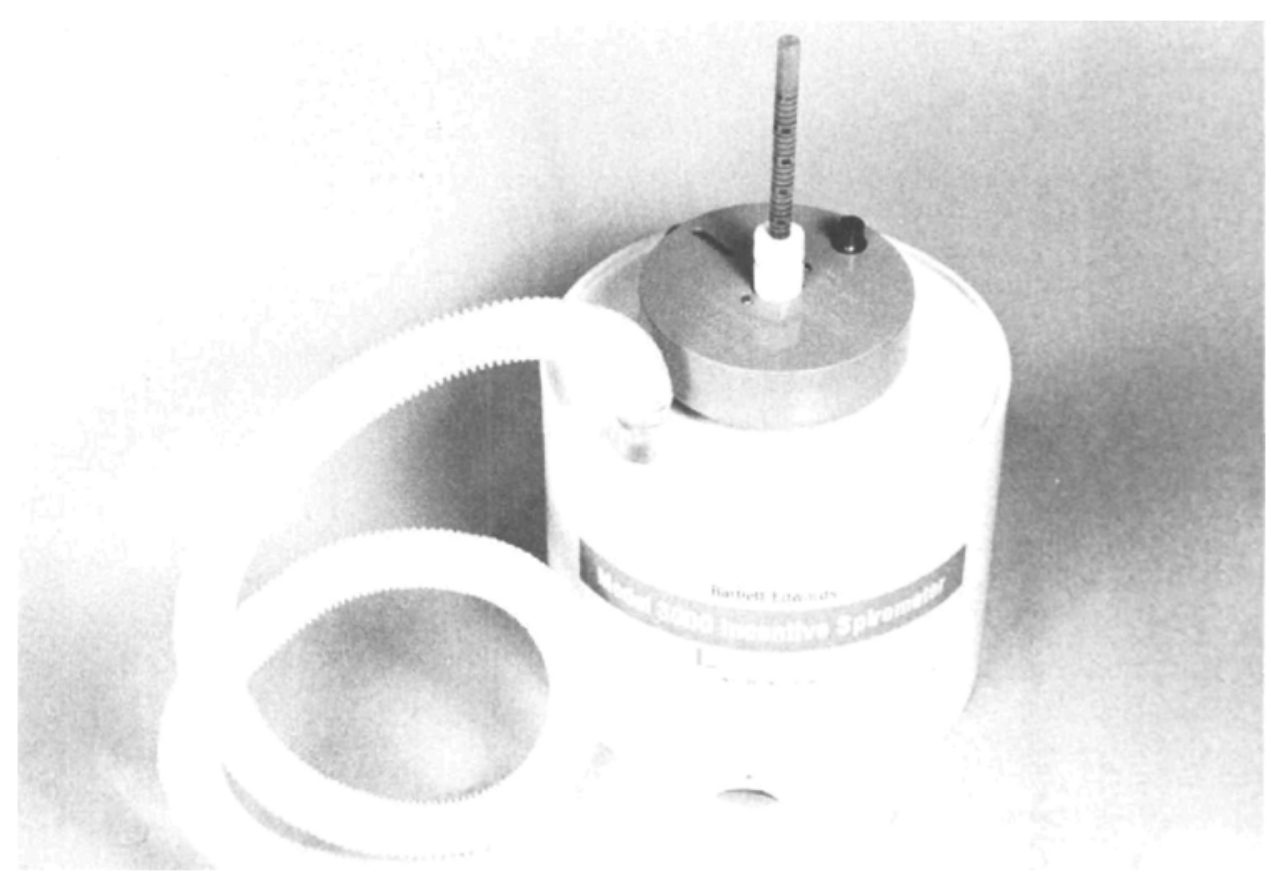


On the day before the operation the vital capacity was measured with a Wright flowmeter to provide a baseline for post-operative treatment. The patient was then trained in the use of the incentive spirometer ${ }^{5}$ and the vital capacity was measured again. Following the operation and after the trachea had been extubated the patient was placed on treatment with the incentive spirometer four times a day. All treatments were carried out with the patients sitting on the edge of the bed except when the intra-aortic balloon pump was still in use, in which case they remained supine. Between treatments the patients were nursed with the head of the bed raised $20^{\circ}$ to $30^{\circ}$, as tolerated, to make breathing easier.

The treatment was continued on all patients while still in the Intensive Care Unit and longer on those with clinical signs of atelectasis. A Puritan humidifier was used to provide oxygen at a concentration which was expected to provide a $\mathrm{Pa}_{0.2}$ of 100 to $120 \mathrm{~mm} \mathrm{Hg}$ ( 13 to $16 \mathrm{kPa}$ ). The following observations were made:

(1) Clinical progress, results of physical examination of the chest, temperature, pulse and respiratory rate were recorded.

(2) Pre-operative chest films were reviewed and post-operative films which were taken early after operation, at 24 and 48 hours and every two days thereafter unless required more frequently. A short time-exposure of one-twentieth of a second or less was used with a high kilovoltage technique to ensure good films. After extubation, films were taken in the upright position with additional lateral views.

(3) The vital capacity was measured before and after pre-operative training in 13 patients and before and after the first and second treatments on the first post-operative day in all patients.

(4) Blood gases were measured in blood taken from a radial artery cannula before, and ten and sixty minutes after the first two post-operative treatments.

\section{Patient Population}

The consecutive series of patients selected were anaesthetized for cardiac operations with extra-corporeal cardiopulmonary bypass by one of the authors of the study. The conditions requiring operation were ischaemic (19), valvular (14), and congenital ( 1 ) heart disease (Table II). The mean age was 47.9 years (range 29-64).

\section{RESULTS}

The effect of operation on vital capacity

The mean vital capacity measured in 21 patients before operation was 2.80 litres. When first measured after operation in the same patients it had fallen to 1.18 litres. The vital capacity after operation was therefore only 41.5 per cent of the pre-operative level.

The effect of the incentive spirometer on vital capacity (Table III)

The mean vital capacity, when measured before and after incentive spirometry on the first post-operative day in 34 patients had increased by 19.4 per cent and 11.6 per cent respectively with the first and second treatments (average 15.5 per cent; $\mathrm{P}<0.001$ ). 
TABLE II

The Operations Performed on the Patients in this Study

\begin{tabular}{lr}
\hline \hline Aorto-coronary bypass & 11 \\
Aorto-coronary bypass with intra-aortic balloon & 5 \\
Mitral and aortic value replacement & 5 \\
Mitral valve replacement & 4 \\
Aortic valve replacement & 4 \\
Aortic valve replacement and right aorto-coronary bypass & 1 \\
Infarctectomy of left ventricle & 1 \\
Resection of left ventricular aneurysm & 1 \\
Anastomosis of internal mammary to left anterior descending coronary & 1 \\
artery & 1 \\
Patch of ventriculo-septal defect and infundibulectomy of right ventricle & Total \\
& 34 \\
\hline
\end{tabular}

TABLE III

The Effect of the Incentive Spirometer on Vital Capacity

\begin{tabular}{|c|c|c|c|}
\hline & \multicolumn{2}{|c|}{ Vital capacity } & \multirow[b]{2}{*}{$\begin{array}{l}\text { Increase } \\
\text { (percent) }\end{array}$} \\
\hline & $\begin{array}{c}\text { Before } \\
\text { treatment }\end{array}$ & $\begin{array}{c}\text { After } \\
\text { treatment }\end{array}$ & \\
\hline $\begin{array}{l}\text { First treatment } \\
\text { Second treatment } \\
\text { Average }\end{array}$ & $\begin{array}{l}1002 \pm 74^{*} \\
1094 \pm 71\end{array}$ & $\begin{array}{l}1196 \pm 74 \\
1221 \pm 74\end{array}$ & $\begin{array}{l}19.4 \\
11.6 \\
15.5\end{array}$ \\
\hline
\end{tabular}

*Geometric mean of vital capacity (in $\mathrm{ml}$ ) and its standard error. This table shows that the vital capacity increased after both treatments.

TABLE IV

The Effect of Incentive Spirometer Treatment on Arterial Oxygen Tension

\begin{tabular}{lccc}
\hline \hline & \multicolumn{3}{c}{ Arterial oxygen tension $(\mathrm{mm} \mathrm{Hg})$} \\
\cline { 2 - 4 } & $\begin{array}{c}\text { Before } \\
\text { treatment }\end{array}$ & $\begin{array}{c}\text { Ten minutes } \\
\text { after treatment }\end{array}$ & $\begin{array}{c}\text { Sixty minutes } \\
\text { after treatment }\end{array}$ \\
\hline First treatment & $124.2 \pm 7.7^{*}$ & $116.2 \pm 7.6$ & $122.8 \pm 6.6$ \\
Second treatment & $102.8 \pm 4.5$ & $111.1 \pm 6.6$ & $115.3 \pm 6.1$
\end{tabular}

\footnotetext{
"Geometric mean of arterial oxygen tension $\left(\mathrm{Pa}_{\mathrm{O}_{2}}\right.$ in $\mathrm{mm} \mathrm{Hg}$ ) and its standard
} error.

In 13 patients vital capacity was measured before and after treatment both before and after operation. The increase of vital capacity was similar and significant both before and after operation (14.6 per cent and 12.9 per cent respectively).

\section{The effect of the incentive spirometer on arterial oxygen tension (Table IV)}

The $\mathrm{Pa}_{\mathrm{O}_{2}}$ did not show significant changes 10 to 60 minutes after incentive spirometer treatment but it did tend to fall in the period between the two treatments $(\mathrm{P}<0.05)$.

\section{The diagnosis of atelectasis:}

Atelectasis was correctly diagnosed in $\mathbf{5 0}$ per cent of cases by the presence of poor basal expansion or bronchial breathing. The record of temperature, pulse, and respiration rate was of little value in the early diagnosis of atelectasis because of the high frequency of abnormal signs (Table V) but if there was still pyrexia by 
TABLE V

Abnormal Vital Signs During First Post-operative Week

\begin{tabular}{lrrrrrrrr}
\hline \hline \multicolumn{1}{c}{ Post-operative day } & 0 & 1 & 2 & 3 & 4 & 5 & 6 & 7 \\
\hline Temperature above $38.5^{\circ} \mathrm{C}$ & 30 & 26 & 22 & 14 & 7 & 5 & 4 & 2 \\
Heart rate above 120 per minute & 14 & 8 & 10 & 7 & 4 & 3 & 3 & 1 \\
Respirations above 24 per minute & - & 21 & 16 & 20 & 11 & 9 & 3 & 8 \\
\hline
\end{tabular}

NoTE: Thirty-four patients on incentive spirometer treatment observed during the first week after open-heart surgery in whon vital signs exceeded the critical values. $\mathrm{Day}$ " $\mathrm{O}$ " is the day of operation. One patient was put on a ventilator from day 4 to day 11 and another patient from day 5 to day 26 .

the fourth day atelectasis was always present. Radiological examination showed an overall incidence of atelectasis of 84 per cent (Table VI). Plate changes occurred in 69 per cent of cases, subsegmental changes in 34 per cent and segmental in 9 per cent. Plate atelectasis was combined with subsegmental in six cases and with segmental in three cases. Only one patient had plate, subsegmental and segmental atelectasis. Sixty-six per cent of patients had pleural effusions, all but one of which occurred in patients who also had atelectasis. There was one right basal opacity, possibly consolidation, which subsequently cleared.

\section{Clinical Progress}

Despite the high incidence of abnormal physical and vital signs most patients made good progress and 27 of 34 patients left Intensive Care on or before the fourth day. The average stay was 4.3 days. However, this includes one patient who stayed 30 days on a ventilator because of respiratory failure secondary to left ventricular failure associated with aortic valve disease; excluding him, the average stay in Intensive Care was 3.5 days.

\section{Discussion}

It was found that after cardiac operations the mean vital capacity dropped to only 41.5 per cent of its pre-operative level. This is a greater decrease than has been found after abdominal operations in which Bartlett, et al. found a fall to only 60 per cent of the pre-operative vital capacity. ${ }^{7}$

The incentive spirometer was effective in increasing vital capacity by 19.4 per cent with the first treatment and by 11.6 per cent with the second treatment. Fatigue probably contributed to the lower vital capacity at the second treatment. There was a trend towards lower $\mathrm{Pa}_{\mathrm{O}_{2}}$ between the first and second treatments, which is consistent with the development of atelectasis. If atelectasis is caused by hypoventilation, then it would be expected that deep breathing with the incentive spirometer would reverse this trend. However, arterial oxygen tensions were not significantly altered at ten or sixty minutes after incentive spirometer treatment. This is in contrast to the findings of Bartlett, et al. ${ }^{7}$ who found that the $\mathrm{Pa}_{\mathrm{O}_{2}}$ increased 30 seconds after five yawning manoeuvres and that there was also stepwise increase in $\mathrm{Pa}_{2}$ when yawning was repeated five times at hourly intervals. Bartlett's patients probably performed their treatments in the sitting position because the literature with the Bartlett-Edwards Incentive Spirometer describes this as the preferred position. 


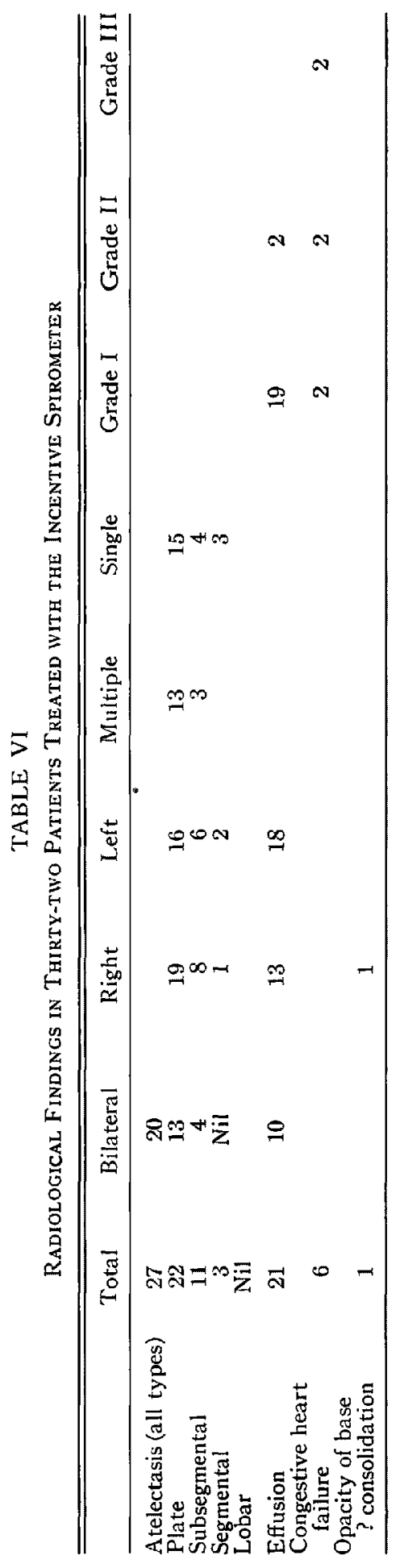


There are two possible explanations for the discrepancy between Bartlett's findings and ours. These are differences of technique and in the selection of patients. Bartlett used air or oxygen to get a constant inspired oxygen tension while in our study oxygen was given by the Puritan mask at whatever concentration was deemed clinically necessary. Increased ventilation may have lowered the inspired oxygen tension by entraining air. It may also be that incentive spirometer treatment four times a day is inadequate. The other possible explanation may lie in the difference between patients after laparotomy and those after operations with cardiopulmonary bypass. The greater physiological impairment after cardiac operations is indicated by the greater fall in vital capacity in this group. The incentive spirometer is less effective in producing large inspiratory volumes if patients are suffering from minor degrees of cerebral depression, so that it becomes less effective in preventing atelectasis. Of course, if patients are mentally confused or unconscious then it is impossible to carry out incentive spirometry (and also intermittent positive pressure breathing treatments), but all patients in this study were able to co-operate satisfactorily.

The effectiveness of therapy on pulmonary atelectasis after cardiac operations would be expected to relate to the aetiology. If the cause of the atelectasis is hypoventilation and a decrease in functional residual capacity, then it should follow that incentive spirometer might be effective therapy. However, if atelectasis is due to loss of surfactant caused by artificial ventilation or lung trauma, or if it is due to a shift of water into the lungs causing closure of small airways, then it would be expected that the incentive spirometer would have limited value. The findings of this study favour the latter conclusion.

The radiological recognition of atelectasis is dependent on the technique employed and the intensity of the search for it. The latter factor is augumented by an index of suspicion or the use of a retrospective method of examination when all the sequential films are available for review. There was a 69 per cent incidence of plate atelectasis in this study, but it is probably of less significance clinically than the subsegmental and segmental atelectasis which had a combined incidence of 45 per cent. Basal plate atelectasis is quite common after upper abdominal surgery and especially at the right base after cholecystectomy. It is therefore not surprising to find a high incidence of basal plate atelectasis after a mid-line thoracotomy and the use of mediastinal chest drains. Chest pain that restricts respiration may be important because atelectasis has been shown after acute myocardial infarction in which a rate of atelectasis of 21 per cent was found (mostly plate but with a few subsegmental type).$^{10}$ Despite the high incidence of plate atelectasis, most patients made good progress and 79 per cent left Intensive Care on or before the fourth post-operative day.

\section{Conclusion}

In patients who had undergone open-heart surgery this study failed to show an increase in the $\mathrm{Pa}_{\mathrm{O}_{2}}$ at 10 minutes and one hour after the use of the incentive spirometer, despite an increase in the vital capacity. This suggests that this therapy did not reduce the trend towards hypoxia which, in these patients, is due to pulmonary shunting resulting from atelectasis. 
In order to assess the incentive spirometer further it is proposed to compare it in a randomized study with a control group which will be treated with intermittent positive pressure breathing (IPPB). To gain more accurate measurements a mask with a constant inspired oxygen tension ${ }^{11}$ and a Vitalor spirometer will be used.

The incidence of atelectasis demonstrated radiologically was total 84 per cent, plate 69 per cent, subsegmental 34 per cent and segmental 9 per cent. Clinical progress was good with 79 per cent of cases leaving Intensive Care within four days. The effect of a large positive fluid balance in causing atelectasis is considered a likely contributing factor.

\section{SUMMARY}

A preliminary assessment of the effectiveness of the Bartlett-Edwards incentive spirometer was made using it as part of the post-operative treatment of 34 patients after open-heart surgery. Its effects on atelectasis were assessed by measuring vital capacity, arterial oxygen tensions, clinical signs and radiological changes. It was found that vital capacity fell after surgery to 41.5 per cent of the pre-operative level, but this rose after the use of the incentive spirometer by an average of 15.5 per cent. Arterial oxygen tensions were unaltered by the use of the incentive spirometer. Temperature, pulse and respirations were of little help in the early diagnosis of atelectasis, but all patients who were still pyrexic four days after operation showed radiological evidence of atelectasis. The incidence of atelectasis demonstrated radiologically was total 84 per cent and plate 69 per cent, subsegmental 34 per cent and segmental 9 per cent.

The implications of these findings are discussed.

\section{RÉsumé}

Nous avons effectué une évaluation préliminaire de "l'Incentive Spirometer" de Bartlett-Edwards chez 34 opérés ayant subi une chirurgie à cœur-ouvert. Son influence sur l'atélectasie pulmonaire, au point de vue prévention ou évolution, a été évaluée au moyen de mesures des capacités vitales, des $\mathrm{Pa}_{\mathrm{O}_{2}}$, des signes cliniques et radiologiques.

Nous avons trouvé que la capacité vitale tombait après la chirurgie à 41.5 pour cent du niveau pré-opératoire; elle remontait d'environ 15 pour cent - utilisant ce spiromètre. Les $\mathrm{Pa}_{\mathrm{O}_{2}}$ n'étaient cependant pas modifiées par l'usage du spiromètre. La température, le pouls et la fréquence de la respiration étaient peu contributoires au diagnostic précoce de l'atélectasie, mais tous les patients qui présentaient encore de la température quatre jours après l'intervention, avaient des signes radiologiques d'atélectasie. L'incidence radiologique d'atélectasie était de 84 pour cent.

\section{ACKNOWLEDGMENTS}

We are most grateful for support and encouragement in writing this paper from Dr. A.A. Scott, for the statistical analysis from Dr. L. Endrenyi of the Department of Pharmacology of the University of Toronto, and for financial assistance from the Marion Webster Taylor Fund. 


\section{REFERENCES}

1. Provan, J.L., Austen, W.G., \& Scannell, J.G. Respiratory complications after open-heart surgery. J. Thoracic and Cardiovas. Surg, 51: 626 (1966).

2. Gauert, W.B., Anderson, D.S., Reed, W.A., \& Templeton, A.W. Pulmonary complications following extracorporeal circulation. Southern Med. J., 64: 679 (1971).

3. Templeton, A.W., Aliond, C.H., Seaber, A., Smmons, C., \& Mackenzie, J. Postoperative pulmonary patterns, following cardiopulmonary bypass. Am. J. Cardiol. 96I: 1007 (1966).

4. Tursbull, K.W., Miyagishima, R.T., \& Gerein, A.N. Pulmonary complications and cardiopulmonary bypass. A clinical study in adults. Canad, Anaesth. Soc. J., 21 : 181 (1974).

5. Bartlett, R.H., Krop, P., Hanson, E.L., \& Moore, F.D. Physiology of yawning and its application to post-operative care. Surg. Forum 21: (1970).

6. Van de Water, J.M., Watring, W.G., Linton, L.A., Murphy, M., \& Byron, R.L. Prevention of post-operative pulmonary complications. Surg. Cynaecol., Obstet. 135: 229 (1972).

7. Bartlett, R.H., Brennan, M.L., Gazzaniga, A.B., \& Hanson, E.L. Studies on the pathogenesis and prevention of post-operative pulmonary complications. Surg. Gynaecol. Obstet. 137: 925 (1973).

8. Fraser, R.C. \& ParÉ, J.A. Diagnosis of diseases of the chest. Volume 1, 301. W.B. Saunders Company, Toronto (1970).

9. Fleischier, F. Uber das Wesen der basalan horizontalen shattenstreifen in Lungenfield. Wein, Arch.f. inn. Med. 28: 461 (1936).

10. Tudor, J., Maurer, B.J., Wray, R., \& SteiNer, R.E. Lung shadows after acute myocardial infarction. Clinical Radiology 24: 365 (1973).

11. Wexler, H.R., Aberian, A., Scott, A.A., \& Cooper, J.D. Measurement of intratracheal oxygen concentrations during face mask administration of oxygen. A modification for improved control. Canad. Anaesth. Soc. J. 22: 416 (1975). 